\title{
Review on Peste Des Petits Ruminants (Ppr) and its Economic Importance
}

\author{
Seifudin Kassim Ahmed \\ College of Agriculture and Veterinary Medicineschool of Veterinary Medicine, Jimma, Ethiopia \\ *Corresponding Author: Seifudin Kassim Ahmed, College of Agriculture and Veterinary \\ Medicineschool of Veterinary Medicine, Jimma, Ethiopia
}

\begin{abstract}
Peste des petits ruminants (PPR) is a highly contagious viral disease that mainly affects sheep and goats. It is a member of the genus Morbillivirus in the family Paramyxoviridae. Now a day the disease is recognized as responsible for mortality and morbidity across many countries of the world.The disease occurs south of the Sahara desert and north of the equator in Africa, in most of the Middle East and in parts of Asia including much of the Indian subcontinent. It is transmitted by the aerosol route during close contact between animals mainly through sneezing and coughing. The disease is characterized by high fever, ocular and nasal discharge, pneumonia, necrosis and gastrointestinal tract leading to secure diarrhea. Diagnosis can be made on the basis of clinical, pathological and epizootiological findings. It has a significant economic impact on food security and livelihoods. PPR is therefore considered as one of the most damaging of all animal diseases in Africa, the Middle East and Asia, and it is also one of the priority diseases indicated in the FAO-OIE Global Framework for the Progressive Control of Transboundary Animal Diseases. Peste des Petits Ruminants is common in Ethiopia and economic losses are due to loss of production, death, abortion and cost of controlling the disease.There is no specific treatment for PPR; however, drugs that control bacterial and parasitic complications may decrease mortality. For control purpose ring vaccination and/or vaccination of high-risk populations can also be helpful. Therefore, the eradication of PPR is by a combination of quarantine, movement control, cleaning and disinfection of infected premises and vaccination.
\end{abstract}

Keywords: Economic importance, Epidemiology,Peste des petits ruminants, sheep and goat

\section{INTRODUCTION}

Ethiopia possess a huge number of livestock populations in African continent estimated to be 57.5 million cattle, 31.2 million sheep and 29.8 million goats were found in the country (CSA, 2019). Owing to their high fertility, short generation interval and adaptation even in harsh environments, sheep and goats are considered as an important asset of poor farmers. Small ruminants are exploited in the country for diversepurposes. However, small ruminant production and productivityand producers benefits are far below expectations due to diseases and other factors. A Peste Des PetitsRuminantis Virus (PPRV) is among important diseases affecting the productivity of small ruminant (Abraham et al., 2005).

Peste des petits ruminants (PPR) is a highly contagious viral disease that mainly affects sheep and goats. PPR is a member of the genus Morbillivirus in the family Paramyxoviridae. Four genetic lineages (Lineages 1-4) and a number of viral strains have been identified. Lineage 4 viruses have become especially prevalent in recent years. PPRV is closely related to rinderpest virus, which has been eradicated (CFSPH, 2015). Domestic animals such as sheep and goat, camel, cattle and pigs can be affected by PPR with a various degree of susceptibility (Diallo, 2006).

It was in 1977 that PPR clinically suspected for the first time in Ethiopia in a goat herd in the Afar region, east of the country and later confirmed in 1991 with cDNA probe in lymph nodes and spleen specimens collected from outbreak in a holding near Addis Abeba (Roederet al., 1994). Later on the virus was determined to be genetically to be clustered within lineage III (Banyardet al., 2010).

Peste des petits ruminants (PPR) is transmitted by the aerosol route during close contact between animals mainly through sneezing and coughing (Banyardet al., 2010). The affected animals are important source of transmission during incubation periods, subclinical cases or before the onset of 
clinical signs (Madboli and Ali, 2012). Animals affected by PPR shed the virus in exhaled air, in secretions and excretions from natural orifices approximately 10 days after the onset of fever (Libeauet al., 2014). Spread through ingestion and conjunctiva penetration, by licking of bedding, feed and water troughs are also common. Furthermore, infection may spread to offspring through the milk of an infected dam (Muniret al., 2013).

The disease is characterized by high fever, ocular and nasal discharge, pneumonia, necrosis and gastrointestinal tract leading to secure diarrhea (Aferaet al., 2014). Now a day the disease is recognized as responsible for mortality and morbidity across many countries of the world. Heavy loss can be seen, especially in goats, with morbidity and mortality rates sometimes approaching $80-100 \%$ (Diallo, 2006).

PPR is a widespread, virulent and devastating disease of small ruminants. It has a significant economic impact on food security and livelihoods. PPR is therefore considered as one of the most damaging of all animal diseases in Africa, the Middle East and Asia, and it is also one of the priority diseases indicated in the FAO-OIE Global Framework for the Progressive Control of Tran boundary Animal Diseases (FAO/OIE, 2015). Moreover, serological and clinical evidences were reported by Tibboet al., 2001. Economic losses are due to loss of production, death, abortion and cost of controlling the disease. Heavy losses can be seen, especially in goats; all of the affected animals in some herds may die (Salikiet al., 1994).Therefore strict animal movement control within the country and cross-border should be effective and use of epidemiological intelligence to initially target endemic populations and high-risk areas will be essential (Jilo, 2016).

There for the Objectives of this seminar are:-

- To review peste des petitsruminants and

- To overview the socio-economic importance of PPR.

\section{LITERATURE REVIEW}

\subsection{History}

PPR was first describedin Ivory Coast, West Africa in 1942 and subsequently spread to other regions where it used to be named as Kata, psuedo-rinderpest, pneumoenteritis complex and stomatitis-pneumoenteritis syndrome. In the late 1970s sub-Saharan Africa, then the Middle East and Asia faced severe epidemics respectively (Libeauet al., 2014). The infection has long been considered as caused by a variant of rinderpest virus, adapted to small ruminants but recognition of PPR virus as a novel member of the Morbillivirus genus occurred only in the late 70s by using more sensitive laboratory techniques (Gibbs et al., 1979). Currently, the presence of the virus has been confirmed in large areas of Asia, the Middle East and Africa; moreover, it is spreading to new countries, affecting and threatening an increasing number of small ruminant and livestock keepers (Libeauet al., 2014).

The Strains of PPR virus that cause only sub-clinical diseases have been identified in several areas of the country but it was clinically suspected in Ethiopia in 1977 in a goat herd in the Afar region, in the east of the country (Abraham et al., 2005). PPR introduced to Ethiopia in 1989 in the southern Omo River valley from where it moved east to Borana then northwards along the Rift Valley to Awash. The disease then spread northwards into the central Afar Region and eastwards into the Ogaden (Abraham et al., 2005; Muniret al., 2013). Clinical and serological evidence of its presence has been reported in 1984 and later confirmed in 1991 with cDNA probe in lymph nodes and spleen specimens collected from an outbreak in a holding near Addis Ababa (Roeder et al., 1994). Nowadays, Because of its major economic importance, dramatic clinical incidences with high mortality rate and restrictions on animal and product movements, PPR is considered as a disease of major economic impact and has to be notified to the World Animal Health Organization (OIE) (Albinaet al., 2013).

It has received a growing attention because of its wide spread, economic impacts and the role it plays in complication of the ongoing global eradication of rinderpest and epidemiosurveillance programmes (Couacy-Hymannet al., 2002).

\subsection{Etiology}

PPR caused by an RNA coated virus belongs to genus morbillivirus, family Paramyxoviridae and order Mononegavirales (Zakianet al., 2016). Other morbillivirus include Rinderpest virus, Measles 
virus, Canine distemper virus, Porcine distemper virus, Cetacean morbillivirus, the morbillivirus of marine mammals, and Feline morbillivirus (Woo et al., 2012). PPR virus is a small, one strand RNA virus which has 15948 nucleotides and 8 genes (3'-N-P/C/V-M-F-HN-L-5'). These genes are responsible to produce 6 structural proteins, $\mathrm{N}$-(nucleocapsid), $\mathrm{P}$-(phosphoprotein), M-(matrix protein), F-(fusion protein), $\mathrm{HN}$-(haemagglutininaminidase protein), L-(large/ polymerase) and two nonstructural proteins (protein C and protein V) (Bailey et al., 2005; Rahamanet al., 2003; Zakianet al., 2016).

GenomicRNA is wrapped by the nucleoprotein (N) to form the nucleocapsid into which are associated two other viral proteins: the phosphoprotein $(\mathrm{P})$ and the large protein (L). The haemagglutination allows the virus to bind to the cell receptor during the first step of the viral infection process. By their positions and their functions, both $\mathrm{F}$ and $\mathrm{H}$ are very important for the induction of protective host immune response against the virus. However $\mathrm{N}$ the most abundant and also the most immunogenic among PPRV proteins, does not induce protective immunity against the virus. It has been usedin the development of diagnostic tests (Diallo, 2006). The nucleocapsids have a characteristic herring-bone appearance. Morbilliviruses are linear, non-segmented, single stranded, negative sense RNA viruses with genomes approximately $15-16 \mathrm{~kb}$ in size and $200 \mathrm{~nm}$ diameters (Rima et al., 2005).

PPRV strains that have been identified by different laboratories so far are divided into four phylogenetic lineages designated I to IV according to the sequence data derived from the nucleoprotein or from the fusion protein genes (OIE, 2013).

(a)

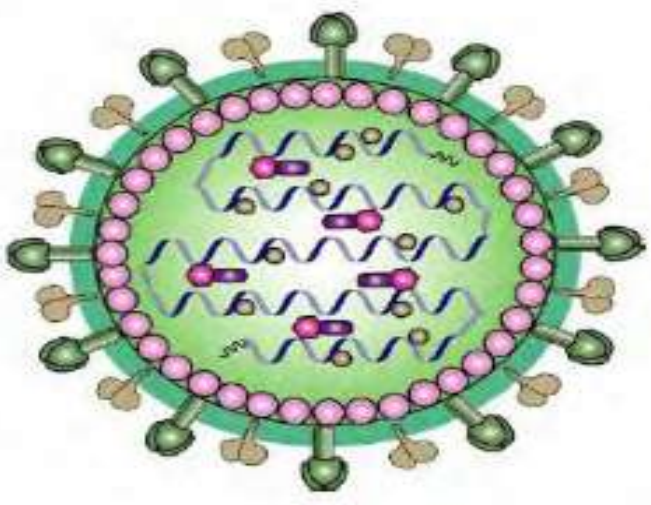

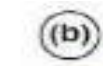

Fusion (F) protein

Haemagglutininneuraminidase $(\mathrm{HN})$ protein

- Nucleacapsid (N) protein

Matrix (M) protein

Q Large $(L)$ protein

Phosphoprotein (P)

$\sim \sim$ Viral RNA

(c)

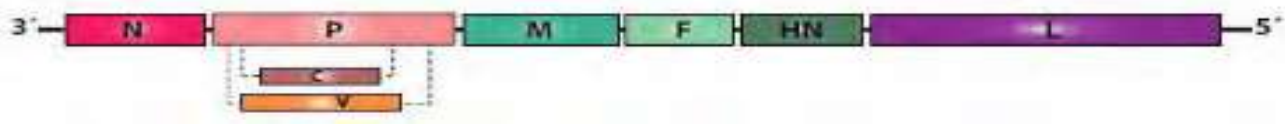

Figure1. (a) Schematic structure of a typical morbillivirus (PPRV). (b) The structural components of PPR. (c)

The genome organization of all known genes of PPRV.

Source: (Dejene, 2016)

\subsection{Epidemiology}

\subsubsection{Host Range}

Domestic animalssuch as sheep and goats, camel, cattle and pigs aresusceptible to PPR in a variety of degrees. ClinicallyPPR is seen in both sheep and goats however, goats aremore susceptible than sheep (Adel et al., 2004).Camels are considered susceptible to PPR but this is still to be clarified by experimental infections. It has been shown that camels can seroconvert to the PPRV (Roger et al., 2001). Recent observations in Sudan suggest that camels could be affected by PPR, as they can show clinical expression of the disease and positive results were detected by serological tests, including reverse transcription polymerase chain reaction (RT-PCR), and PPRV was isolated in cell culture (Khalafallaet al., 2010; Kwiateket al., 2011). In one study, antibodies against PPR were detected in Ethiopia in $3 \%$ of the 628 tested camels (Abraham et al., 2005). 
Peste des petits ruminants can affect some wild ungulates, but there is very limited information on species susceptibility and the occurrence of disease. Peste des petits was confirmed as the cause of two severe outbreaks, one in captive Dorcas gazelles (Gazelladorcas) and Thomson's gazelles (Gazellathomsoni) in Saudi Arabia in 2002 and the other in buffalo in India in 1995. It is also thought to have caused another outbreak that affected both gazelles and deer in Saudi Arabia in the 1980s. White-tailed deer (Odocoileusvirginianus) can be infected experimentally. In addition, peste des petits ruminants have been reported in captive Nubian ibex, Laristan sheep and gemsbok. Whether wild ruminants are important in the epidemiology of this disease is unknown (OIE, 2008).

\subsubsection{Risk Factors}

Kids over 4 months and under 1 year of age are most susceptible to the disease. Sahelian breeds of sheep and goats are believed to be more resistant than the dwarf breeds in the humid and sub-humid zones of West Africa. In a particular flock, the risk of an outbreak is greatly increased when a new stock is introduced or when animals are returned unsold from livestock markets. Recovered animals have lifetime immunity(Radostitset al., 2007).

Confinement and restricted movement of the animals, due to rainy seasons in tropical countries, may affect the nutritional status of the animals and hence predispose them to PPRV infection. Sero positive PPR cases were reported during the months of December, January and February followed by the months of September and October. December to February appeared to be the period of high risk for small ruminants to PPR infection. The least seroprevalence was observed from March to August. The migration of animals during the coolest months may be one of the reasons for the higher frequency of PPR outbreaks during the months of December, January and February. However, limited fodder also makes animals nutritionally deficient, resulting in an increased susceptibility to further infections. Climatic factors favorable for the survival and spread of the virus may also contribute to the seasonal distribution of PPR outbreaks. With the start of the rainy season between (June/July and August/September), the migratory activity of animals is reduced due to the increased availability of local fodder. The nutritional status of the animals is also improved; resulting in an increased resistance to infection. These factors may play a key role in limiting the transmission of disease. PPR prevail throughout the year in the country (Dharet al., 2002; Brindhaet al., 2001).

Climatic condition is also a major factor and outbreaks are most frequent during the rainy season or the cold dry season. In subtropical areas, the occurrence of the disease is more common during winter and rainy seasons (Kwiateket al., 2007; Dharet al., 2002, Brindhaet al., 2001).The disease has been associated with increased animal movement for commercial and trade purposes, transhumance and nomadic customs, climatic changes and extensive farming practices (FAO,2008; Dejene, 2016).

\subsubsection{Geographic Distribution}

PPR is widely spreader in the intertropical regions of Africa, Arabian Peninsula and Middle East and Asia (Kaukarbayevich, 2009). Previously it was considered that PPR confined to West Africa but later on it has expanded to cover large regions of Africa, the Middle East and Asia by chronological spread from West Africa to Eastward (Khan et al., 2006). However, this does not necessarily mean that PPR originated in West Africa (Brown, 2011) rather, the global spread of PPR is probably related to the progressive control and eradication of rinderpest as cessation of rinderpest vaccination campaigns and loss of antibody cross-protection between the two diseases consequently, small ruminants are fully exposed to PPR (Kamissokoet al., 2013).

Based on the sequence analysis of $\mathrm{F}$ and most divergent $\mathrm{N}$ genes (most appropriate for molecular characterization) the strains of PPRV can be grouped into four lineages (I-IV), which are genetically distinct (Kwiateket al., 2011). The three first lineages were historically settled in Africa, Lineage III is also common to south part of Middle East countries like Yemen, Qatar and Oman and unexpectedly once southern India (Baron et al., 2011). The fourth lineage was until recently confined to Asia, including Turkey and the Arabic peninsula but within a remarkably short time, it spread to a large part of the African continent (Banyardet al., 2010). Therefore, based on molecular epedimeology currently all four linages are found in Africa while linage III and IV found in Asian continent (Jilo, 2016).

PPR virus exists as a single serotype but at the genetic level is divided into four distinct lineages (IIV) based on the fusion (F) protein gene sequence (Banyardet al., 2010). Lineage number I includes the group of virus strains found in West Africa where the disease was first identified (Côte d'Ivoire) 
and also where the first virus isolation was made (Senegal). Lineage II consists of a group of viruses that were initially found in Nigeria. Lineage III, which was first identified in East Africa, is shared between Africa and the Middle-east on both sides of the Red Sea. Lineage IV, a unique lineage in Asia, covers a large area from Turkey to Southern Asia through the Arabian Peninsula (OIE, 2013).

Currently, the disease is widespread in western, central, eastern and northern Africa and the four genetic lineages are all present in different regions of the African continent. Therefore, based on molecular epidemiology currently all four linages are found in Africa while linage III and IV found in Asian continent (Banyardet al., 2010).

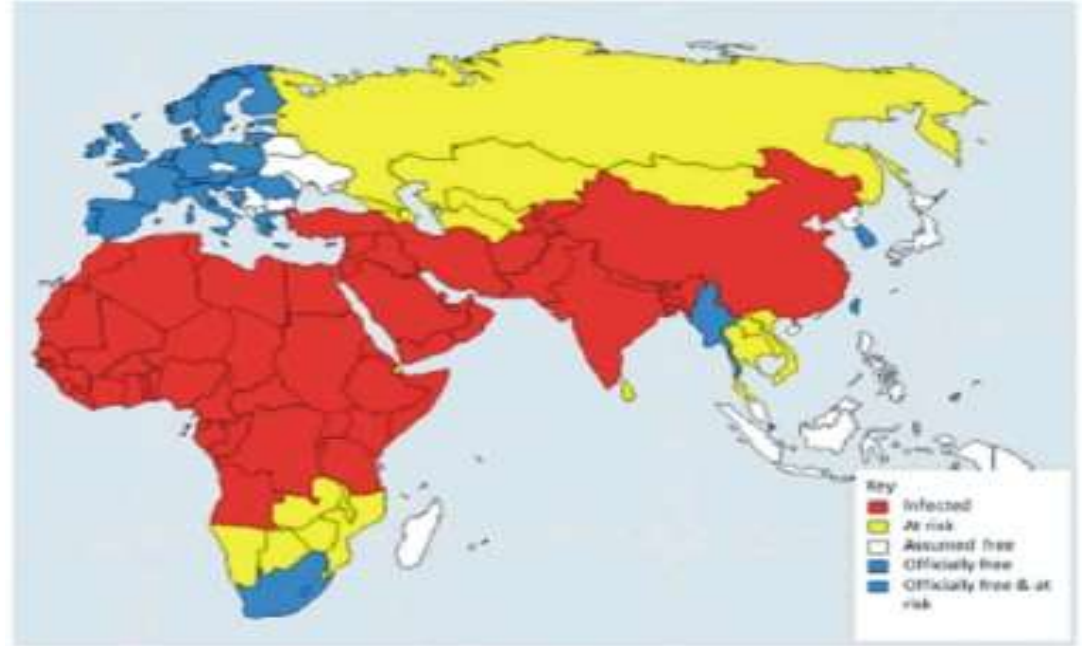

Figure2. Spatial distribution of peste des petits ruminants

Source: (Jones et al., 2016)

\subsection{Transmission}

PPRV is mainly transmitted by the aerosol route during close contact between animals mainly through sneezing and coughing (Banyardet al., 2010). The virus spread through ingestion and conjunctival penetration; by licking of bedding, feed and water troughs are also common. Furthermore, Infection may spread to offspring through the milk of an infected dam (Muniret al., 2013). Moreover, mixed populations sheep and goats, the introduction of new animals into a herd/flock, congregation of susceptible animals at grazing land and watering points and intensive type farming system alimentary facilitate the transmission of this highly contagious disease (Biruk, 2014).

The affected animals are important source of transmission during incubation periods, subclinical cases or before the onset of clinical signs (Madboli and Ali, 2012). PPRV is secreted in tears, nasal discharges, and secretion from coughing and in feces of infected animal. The virus is shed from the intestine and is found in feces at the end stage of the disease approximately 10 days after the onset of fever (Zakianet al., 2016).

\subsection{Morbidity and Mortality}

The morbidity and mortality rates of PPR can be up to $100 \%$ in severe outbreaks but in milder outbreaks, mortality rate may be reduced to $50 \%$ while morbidity rate still remains high in both cases (Fentahun and Woldie 2012). Mortality rate is high in the susceptible young animals (4-8 months), animal with poor nutritional status, Stress and concurrent parasitic and bacterial infections also and enhance the severity of the disease (Alemayehu et al., 2015).

\subsection{Pathogenicity and Immunity}

PPR virus, like other morbilliviruses, is lymphotropic and epitheliotropic consequently; it induces the most severe lesions in organ systems rich in lymphoid and epithelial tissues. The respiratory route is the likely portal to entry. After the entry of the virus through the respiratory tract system, it localizes first replicating in the pharyngeal and mandibular lymph nodes as well as tonsil. Viremia may develop 2-3 days after infection and 1-2 days before the first clinical sign appears. Subsequently viremia results in dissemination of the virus to spleen, bone marrow and mucosa of the gastro intestinal tract and the respiratory system (Radostitset al., 2007). 
Acute disease is usually accompanied by lymphopenia and immuno-suppression, leading to secondary opportunistic infections. The virus can be isolated from nasal discharges from the day ninth of virus infection. PPRV then starts multiplying in the gastrointestinal tract, which leads to stomatitis and diarrhea. Apoptosis of infected cells also seems to play an important role in the pathogenesis of PPRV in goats and sheep (Jilo, 2016).

The surface glycoproteins hemagglutinin $(\mathrm{H})$ and fusion protein $(\mathrm{F})$ of morbilliviruses are highly immunogenic and confer protective immunity. PPRV is antigenically closely related to rinderpest virus (RPV) and antibodies against PPRV are both cross-neutralizing and cross protective. A vaccinia virus double recombinant expressing $\mathrm{H}$ and $\mathrm{F}$ glycoproteins of RPV has been shown to protect goats against PPR disease (Jones et al., 2016) though the animals developed virusneutralizing antibodies only against RPV and not against PPRV. Capripox recombinants expressing the $\mathrm{H}$ protein or the $\mathrm{F}$ protein of RPV or the $\mathrm{F}$ protein of PPRV conferred protection against PPR disease in goats, but without production of PPRV-neutralizing antibodies or PPRV antibodies detectable by ELISA (Berheet al., 2003).

Goats immunized with a recombinant baculovirus expressing the $\mathrm{H}$ glycoprotein generated both humoral and cell-mediated immune responses. The responses generated against PPRV-H protein in the experimental goats are also RPV cross-reactive suggesting that the Hrotein presented by the baculovirus recombinant 'resembles' the native protein present on PPRV. Lymphoproliferative responses were demonstrated in these animals against PPRV-H and RPV-H antigens (Sinnathambyet al., 2001).

Though PPR disease can be effectively controlled by RPV vaccine, rinderpest eradication programmes have been launched in many countries and if these campaigns are successful, Office International des Epizooties (OIE) recommends the cessation of vaccination of all the animals with RPV vaccine so that any residual foci of RPV could be identified. Under these circumstances, small ruminants could only be protected against PPR by using homologous attenuated vaccine. In addition, the successful use of an attenuated PPRV vaccine against RPV has been reported in goats, opening the possibility to use it as a differentiable vaccine for cattle (Couacy-Hymannet al., 2002).

\subsection{Clinical Sign}

The incubation period can range from two to 10 days; in most cases, clinical signs appear in 2-6 days (CFSPH, 2011). Most cases of PPR are acute, with a sudden fever that may last for 5-8 days before the animal either dies or begins to recover. The characteristic signs begin with a clear discharge from the nose that becomes grey and sticky. The discharge from the nose may remain mild or may progress to severe inflammation of the mucous membrane of the nose characterized by the presence of exudates that crust over, blocking the nostrils causing respiratory distress. The nasal mucous membranes may develop small areas of erosion. The conjunctiva may be congested with matted eyelids. The mucous membranes in the mouth may also be eroded. Concurrently, animals will most likely have profuse, non-hemorrhagic diarrhea resulting in severe dehydration, which may progress to emaciation, difficult breathing and die within 5-10 days. Bronchopneumonia with coughing is common late in the disease. Infection of pregnant animals with the virus has also, albeit rarely, been linked to abortion (Abubakaret al., 2008).

The prognosis of acute PPR is usually poor. The severity of the disease and outcome in the individual is correlated with the extent of the mouth lesions. Prognosis is good in cases where the lesions resolve within 2 to 3 days. It is poor when extensive necrosis and secondary bacterial infections result in a fetid odor from the animal's mouth. Respiratory involvement is also a poor prognostic sign. The severity of the disease varies with the species, as well as the animal's immunity to PPRV and its breed. Goats and sheep are not always affected to the same extent during an outbreak (CFSPH, 2011).

Peracute form: Peracute cases can be seen when PPR first occurs in native populations of sheep or goats. In this form, the clinical signs are generally limited to high fever, severe depression and death. More often, peste des petites ruminants'occurance is as sub-acute or acute disease. Domesticated animals other than sheep and goats do not usually become ill. Cattle are usually asymptomatic; however, clinical signs have been reported in experimentally infected calves and it is possible that some cattle in poor condition might become symptomatic. If they did, the syndrome would probably resemble Rinderpest. Respiratory disease was reported in camels during an outbreak that may have 
been complicated by Streptococcus equi. Experimentally infected pigs remain asymptomatic (CFSPH, 2011; Hamdyet al., 2004). Clinical signs have been described for a few exotic species. The initial signs were anorexia and depression, followed by fever, lacrimation, congested mucous membranes, nasal discharges, salivation and diarrhea. All affected animals died. A highly fatal outbreak in goat was characterized by depression, profuse salivation, conjunctival congestion and febrile (CFSPH, 2011).

Acute form: The disease usually appears in the acute form, with an incubation period of 2 to 10 days followed by a sudden rise in body temperature to $104-106^{\circ} \mathrm{F}\left(40-41^{\circ} \mathrm{C}\right)$. The temperature usually remains high for about 5 to 8 days before slowly returning to normal proceeding recovery or dropping below normal before death. Affected animals appear ill and restless and have a dull coat, dry muzzle and depressed appetite. Accompanying these nonspecific signs is a series of changes that make up a highly characteristic syndrome. From the onset of fever, most animals have a serious nasal discharge, which progressively becomes mucopurulent. The discharge may remain slight or may progress, resulting in a profuse catarrhal exudate, which crusts over and occludes the nostrils. At this stage, animals have respiratory distress and there is much sneezing in an attempt to clear the nose. Small areas of necrosis may be seen on the visible nasal mucous membranes. The conjunctiva usually becomes congested and the medial canthus may have some crusting. As with the nose, there may be profuse catarrhal conjunctivitis resulting in matting of the eyelids (Bruning-Richardson, 2011).

Sub-acute form:The sub-acute form, usually occurs in sheep, but also possible in goats. Necrotic ulcers are not obvious and most of the affected animals are recovered. Death is rare. The disease duration is usually more than two weeks (Abraham, 2005).

\subsection{Pathologic Lesion}

Necrotic stomatitis is common. It starts as small, roughened, red, superficial necrotic foci on the gum below the incisor teeth. These areas may resolve within 48 hours or progressively increase to involve the dental pad, the hard palate, cheeks and their papillae and the dorsum of the anterior part of the tongue. Necrosis may result in shallow irregular no hemorrhagic erosions in the affected areas of the mouth and deep fissures on the tongue. Necrotic debris may collect at the oral commissures and scabs may form along the mucocutaneous junction of the lips. There may be excessive salivation but not to the extent of drooling. At the height of development of oral lesions, most animals manifest severe diarrhea, often profuse but not hemorrhagic. As it progresses, there is severe dehydration, emaciation and dyspnea followed by hypothermia and death usually occurs after a course of 5 to 10 days. Bronchopneumonia, evidenced by coughing, is a common feature in the later stages of PPR. Pregnant animals may abort. Secondary latent infections may be activated and complicate the clinical picture (Ezeibe, 2008).

The pathology caused by PPR is dominated by inflammatory and necrotic lesions in the mouth and the gastrointestinal tract. Unlike RP, there is also a definite, albeit inconstant, respiratory system component; hence, the synonym stomatitis pneumoenteritis complex. Emaciation, conjunctivitis, erosive stomatitis involving the inside of the lower lip and adjacent gum, cheeks near the commissures and the free portion of the tongue are frequent lesions. In severe cases, lesions may also be found on the hard palate, pharynx and upper third of the esophagus. The necrotic lesions do not evolve into ulcers because the basal layer of the squamous epithelium is rarely penetrated. The rumen, reticulum and omasum rarely have lesions. Sometimes, there may be erosions on the pillars of the rumen. The abomasum is a common site of regularly outlined erosions and often oozes blood (Salikiet al., 1994).

Lesions in the small intestine are generally moderate, being limited to small streaks of hemorrhages and, sometimes, erosions in the first portion of the duodenum and the terminal ileum. Peyer's patches are the site of extensive necrosis, which may result in severe ulceration. The large intestine is usually more severely affected with congestion around the ileocecal valve, at the ceco-colic junction and in the rectum. In the posterior part of the colon and the rectum, discontinuous streaks of congestion ("zebra stripes") form on the crests of the mucosal folds. In the respiratory system, small erosions and petechiae may be visible on the nasal mucosa, turbinate, larynx and trachea. Bronchopneumonia may be present, usually confined to the anteroventral areas and is characterized by consolidation and atelectasis. There may be pleuritis, which may become exudative and results in hydrothorax. The spleen may be slightly enlarged and congested. Most lymph nodes throughout the body are enlarged, 
congested and edematous. Erosive vulvovaginitis similar to the lesions in the oral mucocutaneous junction may be present. The postmortem lesions are characterized by inflammatory and necrotic lesions in the oral cavity and throughout the gastrointestinal tract (Radostitset al., 2007).

The carcass is often emaciated and/or dehydrated and may have evidence of diarrhea and serous or mucopurulentoculonasal discharges. The lips often have prominent crusty scabs and necrotic stomatitis is common. The lymph nodes, particularly those associated with the respiratory and gastrointestinal tracts are generally congested, enlarged and edematous. In peracute cases, the lesions may be limited to congestion of the ileocecal valve and bronchopneumonia (CFSPH, 2011).

Similar lesions have been reported in buffalo and gazelles. Hemorrhagic and edematous gastroenteritis (involving the abomasum and all segments of the intestines) was reported in infected buffalo. In gazelles, small erosions were found on the tongue and the esophagus contained thick mucoid deposits along the walls. The papillae of the rumen were congested (OIE, 2008).

The abomasum was severely affected, with tiny hemorrhagic erosions, marked congestion and edema in the pyloric region. Congestion, hemorrhages and small erosions were found in the duodenum and congestion was seen in the jejunum. The Peyer's patches appeared shallow and were hyperemic at their edges. Congestion was seen around the ileocecal valve. The mucosal of the colon and rectum were congested, with a 'zebra stripe' pattern. Congestion was also reported in the liver, kidney, pancreas and brain. Froth was found in the trachea and bronchi and the lungs were congested. The lymph nodes and spleen were small. Unilateral corneal opacity was reported in one animal (Kahn and Line, 2006).

\subsection{Diagnosis}

PPRV is routinely diagnosed on the basis of case history, geographic location, clinical examination, gross pathology and histological findings but clinical signs and lesions can be misleading for PPR diagnosis since a number of diseases including rinderpest, contagious caprinepleuropneumonia, bluetongue, Pasteurellosis, contagious ecthyma, foot and mouth disease, heartwater, coccidiosis, Nairobi sheep disease and mineral poisonings have similar out comes (OIE, 2013).

Since sheep and goat are infected by both PPR and Rinderpest, it is difficult to diagnosis both disease tentatively alone, therefore laboratory techniques should have to be used. The laboratory techniques used for the detection of the virus includes virus isolation, detection of viral antigens, nucleic acid sequencing and detection of specific antibody in serum (Nyamweyaet al., 2009; Megersaet al., 2011).

In live animals, swabs are made of the conjunctival discharges and from the nasal and buccal mucosae. During the very early stage of the disease, whole blood is also collected in anticoagulant for virus isolation, polymerase chain reaction (PCR) and haematology. At necropsy (two to three animals), lymph nodes, especially the mesenteric and bronchial nodes, lungs, spleen and intestinal mucosae should also be collected aseptically, chilled on ice and transported under refrigeration. Fragments of organs collected for histopathology are placed in $10 \%$ formalin. At the end of the outbreak, blood can be collected for serological diagnosis (OIE, 2008).

\subsubsection{Virus Isolation}

Recovery of PPR virus is not always successful. But, virus isolation in cell culture can be attempted with several different cell lines. African green monkey kidney cells (Vero-cell) have been used for a long time as the cells of choice for the isolation and propagation of PPRV (Mahapatraet al., 2006). However, some isolates may not grow well in these cells. Recently, transformed monkey cells expressing sheep/goat Signaling Lymphocytic Activation Molecules (SLAM) have been shown to possess increased sensitivity. Techniques for virus isolation cannot be used as routine diagnostic tests as they are time-consuming and cumbersome. Moreover, the preservation of samples collected under field conditions is not always adequate for successful laboratory results (OIE, 2012).

\subsubsection{Antigen Detecting Methods}

Peste des petits ruminates virus antigens can be detected by using an Immune Capture ELISA (ICELISA) (OIE: 2008), Counter Immune Electrophoresis (CIEP) or Agar Gel Immune 
Diffusion (AGID) (Osman et al.,2008), haem-agglutination tests (Ezeibeet al., 2008, Osman et al.,2008), latex agglutination tests and immune fluorescence (Singh et al.,2004). Immuno-capture ELISA and counter immune electrophoresis assays can distinguish between PPRV and RPV. Although AGID test is simple and cheap, it cannot differentiate PPRV and RPV due to its less sensitivity (Osman et al., 2008). But, Immuno-capture ELISA is a rapid, sensitive and virus specific test for PPRV antigen detection and it can differentiate between RP and PPR viruses. Moreover, it is more sensitive than AGID (Abraham et al., 2005).

\subsubsection{Detection of Antibody}

The Competitive ELISA (c-ELISA) based on Monoclonal Antibodies (MAbs) against the $\mathrm{N}$ or $\mathrm{H}$ proteins and virus neutralization tests (VNT) (Singh et al.,2004;Muniret al., 2013) are the most important diagnostic techniques used for the detection of antibodies to PPRV. Currently, cELISA is the most commonly used diagnostic techniques for PPRV antibody detection. The overall specificity of c-ELISA test is $98.4 \%$ with a sensitivity of $92.2 \%$ when compared with VNT. Sensitivity of the assay was taken as proportion of positive samples out of actual positive Sample (Singh et al., 2004).

\subsubsection{Nucleic Acid Sequencing}

Molecular detection of PPRV is performed by using loop-mediated isothermal amplification techniques (Ezeibeet al., 2008) and a Real-Time Polymerase Chain Reaction (RT-PCR) assay based on sequence of the N protein gene. From those methods RT-PCR assay based on sequence of the N protein gene is the most and rapid methods for viral Nucleic acid sequencing (Batten et al., 2011; Aferaet al., 2014).

\section{Differential Diagnosis}

Rinderpest: Clinical RP is rare in goats and sheep in Africa. In India, these species are quite often involved in RP outbreaks. Clinically, RP and PPR are similar, but the former should be the prime suspect if the disease involves both cattle and small ruminants. Confirmation requires virus isolation and cross-neutralization (Hamdyet al., 2004).

Pasteurellosis: Enzootic pneumonia or the septicemic form of pasteurellosis is characterized by obvious respiratory signs, infrequent diarrhea and a fatality rate rarely exceeding 10 percent. Contagious caprinepleuropneumonia, there is no digestive system involvement and the clinical signs and lesions are confined to the respiratory system and pericardium (Hamdyet al., 2004).

Bluetongue: Swelling of the lips, muzzle and oral mucosa, together with edema of the head region, should serve to differentiate bluetongue from PPR. Coronitis is common in bluetongue, is not a feature of PPR. Also, sheep are more affected than goats (Diallo, 2006).

Contagious ecthyma (contagious pustular dermatitis, orf): it is zoonotic disease caused by parapox virus. The orf virus causes proliferative, not necrotic lesions, which involve the lips rather than the whole oral cavity. The absence of nasal discharges and diarrhea also distinguish orf from PPR (Hamdyet al., 2004).

Heart water: There is often central nervous system involvement, including convulsions. There is no diarrhea. Foot-and-mouth disease: caused by an aphthovirus this condition is comparatively mild and the most characteristic clinical sign, lameness, is not a feature of PPR. Nairobi sheep disease: Sheep are more severely affected than goats. It is limited geographically to parts of east and central Africa (Kenya, Uganda, Tanzania, Ethiopia, Somalia and Congo (formerly Zaire)). Diagnosis requires isolation and serologic identification of the virus. Plant or mineral poisoning: Several plants and minerals may cause severe intestinal lesions. Case history and absence of fever should distinguish poisoning fromPPR. Coccidiosis: There is no upper digestive tract and respiratory system involvement (Salikiet al., 1994).

\subsection{Treatment}

There is no treatment for PPR but it helps to give broad spectrum antibiotics to stop secondary bacterial complications and supportive treatment like dextrose normal saline for restoration of body ionic fluid balance (Jilo, 2016). Affected goat with stomatitis, enteritis and pneumonia were treated with penicillin and streptomycin reinforced with broad-spectrum chloramphenicol. However, 
mortality rates can be reduced by the use of drugs that control the bacterial and parasitic complications. Specifically oxytetracycline and chlortetracycline is recommended to prevent secondary pulmonary infections (CIDRAP, 2003).

\subsection{Prevention and Control}

Control of PPR in non-infected countries may be achieved using classical measures such as restriction of importation of sheep and goats from affected areas or newly introduced animal should be quarantined for three weeks, sanitary slaughter and proper disposal of carcasses and contact fomites and decontamination of affected premises in case of introduction. Control of PPR outbreaks can also rely on movement control (quarantine) combined with the use of focused ("ring") vaccination and prophylactic immunization in high-risk populations (Abraham et al., 2005; Jilo, 2016). Carcass and contact fomites should be buried or burned, barns, tools and other items that have been in contact with the sick animals must be disinfected with common disinfectants such as phenol, sodium hydroxide $2 \%$, virkon as well as alcohol, ether and detergents. Vaccination should be carried before the start of the rainy season and annually in endemic areas (OIE, 2013).

\subsubsection{Vaccination}

Live attenuated vaccines are effective against PPR virus and now widely available. Since the global eradication of Rinderpest, heterologous vaccines should not be used to protect against PPR (Jilo, 2016). It has been withheld from being used because of its interference with the Pan-African Rinderpest Campaign (PARC), since it is impossible to determine if seropositive small ruminants have been vaccinated or naturally infected with RPV (Abraham et al., 2005). Sheep and goats vaccinated with an attenuated strain of PPR or that recover from PPR develop an active life-long immunity against the disease (Jilo, 2016). Several homologous PPR vaccines are available, being cell culture-attenuated strains of natural PPRV (Saravananet al., 2010).

In 1998, the OIE World Assembly (formally OIE International Committee) endorsed the use of such a vaccine in countries that have decided to follow the 'OIE pathway' for epidemiological surveillance for rinderpest in order to avoid confusion when serological surveys are performed. Homologous PPR vaccine attenuated after 63 passages in vero cell was used and produced a solid immunity for 3 years. The PPRV homologous vaccine was found to be safe under field conditions even for pregnant animals and it induced immunity in $98 \%$ of the vaccinated animals. The PPRV vaccine has been tried for protection of cattle against RP and it was found very effective. PPR vaccine seed is available through the Pan African Veterinary Vaccine Centre (PANVAC) at Bishoftu, Ethiopia, for Africa (Abraham et al., 2005).

There have also been two published reports on the preliminary results from recombinant capripoxbased PPR vaccines that are able to protect against both capripox and PPR (Berheet al., 2003; Chen et al., 2010).

Rinderpest and PPRV both belong to morbillivirus with cross reactivity and relatively similar immunological response and clinical feature. Rinderpest is a fatal and acute disease in cattle while in sheep and goat characterized as a subacute and mild disease (Couacyet al., 2002). It is assumed that PPRV is the consequence of rinderpest natural passage in sheep and goat. Seroprevalence surveys showed seropositive case causes a humoral response against PPRV in cattle and buffalo (Abraham et al., 2005).

PPR virus in cattle is now a threat,whether the cattle should be vaccinated to control PPR or not. However, the vaccination of cattle with goats and sheep is not cost beneficial (Zakianet al., 2016).

\subsubsection{Opportunities and Challenges to Eradicate PPR}

PPRV has been proposed as the next candidate after eradication of Rinderpest. Recovering animals always develop a strong life-long immunity clearing the virus (Kerdileset al., 2006). Homologous live attenuated vaccine provides a life-long immunity after a single administration however; it has a low thermal stability with half-life of $2-6 \mathrm{~h}$ at $37^{\circ} \mathrm{C}$ after reconstitution (Diallo, 2006). PPR vaccines currently in use are able to induce protective immunity against all known serotypes; immunity is lifelong, whether due to natural infection or vaccination; infection is transmitted primarily by direct contact and the virus does not persist in the environment; infected animals are infectious for a short period of time and there is no carrier state; while a number of different wildlife ungulate species can 
be infected, there is no evidence to indicate that wildlife populations play an important role in virus maintenance; an effective, robust, safe and affordable vaccine is available; a thermostable vaccine has been developed; and sensitive and specific diagnostic tests are available (Jones et al., 2016).

According to Mariner et al., 2016 considering the wide distribution of PPR and its multiple target host species which have an intense mobility, it will be a long process that cannot exclusively rely on mass vaccination. Goats and sheep are more numerous and reproduce rapidly than cattle, which creates greater challenge for the vaccination strategy. When compared to cattle value of sheep and goat per head is lower with an associated lower investment per head on health care, in spite of playing an important role in food security and livelihoods, utilizing marginal grazing unsuitable for cattle or for crop production. Hence, transmission is mainly by direct contact movement control is effective but is difficult to implement in many of the infected countries where extensive and mobile production systems are common. As experienced from RP theoretically, mass annual vaccination is an effective control measure, but in practice is difficult to achieve and is costly. Therefore, a more effective timebound strategy is required which will achieve eradication and avoid the need for long-term costly control programmers to repeat the achievement deserved on RP. PPR specific epidemiological features and socio-economic considerations will also have to be taken into account and sustained international, coordinated and funded strategy based on a regional approach of PPR control will be the guarantee toward success (Jilo, 2016).

\subsection{Socioeconomic Impact of PPR}

Peste des Petits Ruminantsvirus has a widespread distribution spanning Africa and Asia. These areas encompass much of the developing world that relies heavily on subsistence farming to supply food or goods for trade, and small ruminants provide an excellent supply of both. Unfortunately, in many areas of Asia and Africa, small ruminant production and therefore, the livelihoods of poor farmers is threatened by PPR among other trans-boundary animal diseases (TADs). With its associated high morbidity and mortality, PPRV constitutes one of the major obstacles to subsistence farming (Banyardet al.,2010).

The socio-economic losses associated with PPR mainly result from the high mortality rate that is characteristic of the disease. This negatively affects income from production and value addition in small ruminants marketing chains. Peste des Petits Ruminantsdisease is a constraint to international trade, although this impact is mitigated in local and regional markets due to wide geographic distribution of the disease at present. However, the direct economic losses caused by the disease are aggravated by the sanitary measures imposed by authorities to control animal movement and by trade restrictions on animal by-products (Elsawalhyet al., 2010).

The PPR epidemics can cause mortality rates of $50-80 \%$ in naive sheep and goats populations. Due to the confusion with other diseases, the economic impacts of PPR are probably underestimated, but it is believed that PPR is one of the major constraints of small ruminant farming in the tropic (Abraham et al., 2005). An economic analysis for assessing benefits of vaccination against PPR in Niger revealed that such a programme was highly beneficial with an anticipated net present value (NPV) return in five years of 24 million USD following an investment of two millions USD (Abraham et al.,2005).

According to the study in Afar Regional state, North Eastern Ethiopia Was reported about $63.3 \%$ of the total population of sheep and goats were lost each year due to PPR. The financial loss due to mortality in the affected animal farm was on an average $2,146,875.00$ birr/92,140.56 both in sheep farm and in goat farm (Gizawet al., 2018).

According to the study conducted in Ada'ar and Mile districts of Afar Regional state by Gizawet al., the prevalence of PPR was $92(40.2 \%)$ out of 229 analyzed serum samples (Gizawet al., 2018). Another study conducted in Selected districts of Silte and Guraghe Zones of South Regional state, The Overall prevalence was found to be 29.2\% (114/390) (Hailegebreal, 2018). A study conducted in East shewa and Arsi zones indicates, an overall PPR seropositivity was $48.43 \%$ out of 700 serum samples collected from goats and sheep (Gari, et al., 2017). A cross-sectional study reported by Megersaet al., indicatesthat PPR was widely prevalent in small ruminants in the study areas. All villages, except one in Gambella, had seropositive cases. Such a high prevalence in most of the villages (more than 30\%) suggests a remarkable contagious nature of the disease, covering wide geographic areas and infecting perhaps most of the susceptible animals in affected villages. The overall seroprevalence $(30.5 \%)$ of transmit the virus to susceptible small ruminant population and, 
therefore, the movement of animals plays an important role in the transmission and maintenance of PPRV in nature (Megersaet al., 2011).

Because of the negative economic impact on countries affected by PPR, the disease is one of the priorities among international and regional livestock disease research and control programs (FAO 2012b). The disease has also been ranked by pastoral communities as one of the top ten diseases of small ruminants (Diallo,2006).

It is estimated that one billion small ruminants or about $62.5 \%$ of global domestic small ruminant population is at risk of infection with PPR. However, there are very few economic studies related to the economic impact of the PPR and the data available on losses due to the disease is scanty (FAO, 2009a).

\subsection{PPR Control Measures and Challenges in Ethiopia}

Merkel and Yami (2008) claimed that, currently, the strategy of PPR vaccination is ring vaccination to control the spread of PPR infection to provide a vaccinated barrier between infected animals and clean stock. The intervention is expected to contain the outbreak of the disease and reduce losses. The vaccine is provided by the federal government in coordination with, FAO and several NGO's. Mass annual vaccination programs have also been practiced since 2005 with annual vaccination coverage reaching nearly 6 million heads $(20 \%)$ of small ruminant are vaccinated.

Even though, the National veterinary Institute (NVI) is producing sufficient doses of live attenuated tissue culture homologous PPR vaccine (PPR 75/1 Vero 76, attenuated, freeze dried) to satisfy the vaccination programs, a progressive control campaign based on repeated vaccination of all susceptible small ruminants is difficult and unaffordable. The major challenge in control of PPR in the region is lack of adequate information on the dynamics of the disease in the region and inefficiency in early detection, especially because communities and even most of the animal health workers on ground are not familiar with the disease symptoms and may dismiss it as simple pneumonia, CCPP and Orf (Biruk, 2014).

Furthermore, several agro-ecological conditions accompanied with seasonal occurrence of the disease, movement of infective small ruminants within the country and cross-border particularly, the pastoral areas of Afar, Somali and Oromia are well known for significant movement of small ruminants and other livestock species within these regions, to towards central high lands where important livestock markets and export abattoirs are located. Moreover, a cross-border seasonal movement in search of pasture and water in pastoral areas of Kenyan border is also a great challenge to control this widely spreading disease (Alemayehu et al., 2015). Therefore strict animal movement control within the country and cross-border should be effective and use of epidemiological intelligence to initially target endemic populations and high-risk areas will be essential (Jilo, 2016).

\section{CONCLUSIONS AND RECOMMENDATIONS}

Peste des petits ruminants (PPR) is a highly contagious viral disease caused by Morbilivirus that mainly affects sheep and goats. Goats are severely affected while sheep undergo mild form. In a particular flock, the risk of an outbreak is greatly increased when a new stock is introduced or when animals are returned unsold from livestock markets. There is no specific treatment for the disease.Advances in knowledge and development/ design of control tools for PPR disease including diagnostics and vaccines provide an excellent prospect for improved control programs. Economically it is the most important small ruminant disease. The major challenge in control of PPR in the region is lack of adequate information on the dynamics of the disease in the region and inefficiency in early detection. In Ethiopia beside seasonal occurrences of the disease illegal animal movement within and across the borders is a great hindrance for prevention and control of the disease.Therefore, it is very important to support and implement control programs so as to prevent further spread of the disease.

Based on the fact and information mentioned in the review the following recommendations are forwarded.

- Farmers/pastoralists should keep newly purchased sheep and goats separate from other animals.

- Illegal animal movement in the country and across the border should be controlled.

- Regular mass vaccination should be carried out.

- Strategic disease eradication started should be held throughout the country as programmed. 


\section{REFERENCES}

[1] Abraham, G., Sintayehu, A., Libeau, G., Albina, E., Roger, F., Laekemariam, Y., Abayneh, D. and Awoke, K.M. (2005): Antibody seroprevalences against peste des petits ruminants (PPR) virus in camels, cattle, goats and sheep in Ethiopia. Preventive veterinary medicine, 70(1-2): 51-57.

[2] Abubakar, M., Jamal, S.M., Hussain, M. and Ali, Q.(2008): Incidence of peste des petits ruminants (PPR) virus in sheep and goat as detected by immuno-capture ELISA (Ic ELISA). Small ruminant research, 75(2-3): 256-259.

[3] Adel, A.A., Abu-Elzein, E., Al-Naeem, A.M. and Amin, M. (2004): Serosurveillance for peste des petits ruminants (PPR) and rinderpest antibodies in naturally exposed Saudi sheep and goats. Veterinarskiarhiv, 74(6): 459-465.

[4] Afera, B., Hussien, D. and Amsalu, K. (2014): Seroprevalence of peste des petits ruminants in goats of southern parts of Tigray region. Global Veterinaria, 12: 512-516.

[5] Albina, E., Kwiatek, O., Minet, C., Lancelot, R., de Almeida, R.S. and Libeau, G. (2013): Peste des petits ruminants, the next eradicated animal disease. Veterinary microbiology, 165(1-2): 38-44.

[6] Alemayehu, G., Hailu, B. and Seid, N. (2015): Participatory assessment of major animal health constraints to sheep export from Afar Pastoral Production System. Global Veterinaria, 15(1): 48-56.

[7] Bailey, D., Banyard, A., Dash, P., Ozkul, A. and Barrett, T. (2005): Full genome sequence of peste des petitsruminants virus, a member of the Morbillivirus genus. Virus research, 110(1-2): 119-124.

[8] Banyard, A.C., Parida, S., Batten, C., Oura, C., Kwiatek, O. and Libeau, G. (2010): Global distribution of peste des petitsruminants virus and prospects for improved diagnosis and control. Journal of general virology, 91(12): 2885-2897.

[9] Batten, C.A., Banyard, A.C., King, D.P., Henstock, M.R., Edwards, L., Sanders, A., Buczkowski, H., Oura, C.C. and Barrett, T. (2011): A real time RT-PCR assay for the specific detection of Peste des petitsruminants virus. Journal of virological methods, 171(2): 401-404.

[10] Berhe, G., Minet, C., Le Goff, C., Barrett, T., Ngangnou, A., Grillet, C., Libeau, G., Fleming, M., Black, D.N. and Diallo, A. (2003): Development of a dual recombinant vaccine to protect small ruminants against peste-des-petits-ruminants virus and capripoxvirus infections. Journal of virology, 77(2): 1571-1577.

[11] Biruk, A. (2014): Epidemiology and identification ofpeste des petits ruminants (PPR) virus circulating in small ruminants of eastern amhara region bordering afar, ethiopia (Doctoral dissertation, Addis Ababa University).

[12] Brindha, K., Raj, G.D., Ganesan, P.I., Thiagarajan, V., Nainar, A.M. and Nachimuthu, K. (2001): Comparison of virus isolation and polymerase chain reaction for diagnosis of peste des petits ruminants. Actavirologica, 45(3): 169.

[13] Brown, C., (2011): Transboundary diseases of goats. Small Ruminant Research, 98(1): 21-25.

[14] Centere for Food Security and Public Health (CFSPH), (2011): Peste des Petits Ruminants. Lowa State University: CFSPH; Peste des Petits Ruminants.

[15] Centere for Food Security and Public Health (CFSPH), (2015): Public Health. The Center for Food Security, pp. 33.

[16] Chen, W., Hu, S., Qu, L., Hu, Q., Zhang, Q., Zhi, H., Huang, K. and Bu, Z.(2010): A goat poxvirusvectored peste-des-petits-ruminants vaccine induces long-lasting neutralization antibody to high levels in goats and sheep. Vaccine, 28(30): 4742-4750.

[17] CIDRAP, (2003): Peste des Petits Ruminants. Center for infectious diseases research and policy (CIDRAP): Academic health center, University of Minnesota. (Accessed on 22 March 2017). athttp://www.cidrap.umn.edu/cidrap/content/biosecurity/agbiosec/anim.disease/ppr.html.

[18] Couacy-Hymann, E., Roger, F., Hurard, C., Guillou, J.P., Libeau, G. and Diallo, A. (2002): Rapid and sensitive detection of peste des petits ruminants virus by a polymerase chain reaction assay. Journal of virological methods, 100(1-2): 17-25.

[19] Dhar, P., Sreenivasa, B.P., Barrett, T., Corteyn, M., Singh, R.P. and Bandyopadhyay, S.K. (2002): Recent epidemiology of peste des petitsruminants virus (PPRV). Veterinary microbiology, 88(2): 153-159.

[20] Diallo, A.(2006): Control of peste des petits ruminants and poverty alleviation. Journal of Veterinary Medicine, Series B, 53: 11-13.

[21] Elsawalhy, A., Mariner, J.C., Chibeu, D., Wamway, H., Wakhusama, S., Olaho-Mukani, W. and Toye, P.G. (2010): Pan African strategy for the progressive control of Peste des petits ruminants (Pan African PPR strategy).

[22] Ezeibe, M.C.O., Okoroafor, O.N., Ngene, A.A., Eze, J.I.,Eze, I.C. and Ugonabo, J.A.C. (2008): Persistent detection of peste de petitsruminants antigen in the faeces of recovered goats. Tropical animal health and production, 40(7): 517-519.

[23] FAO, (2009a): Peste des Petits Ruminants (PPR). A challenge for small ruminant production. 
[24] FAO, (2009b): Transboundary Disease. Bulletin 33.

[25] FAO, (2012b): Strategy for Progressive Control of PPR in Ethiopia, December, 2012, Addis Ababa, Ethiopia.

[26] FAO/OIE, (2015): Global Frame Work for the Progressive Control of Transboundary Animal Diseases (GF-TADs FAO).

[27] Gari, G., Serda, B., Negesa, D., Lemma, F., and Asgedom, H. (2017): Serological Investigation of Peste Des Petits Ruminants in East Shewa and Arsi Zones, Oromia Region, Ethiopia. Veterinary Medicine International, 2017: 5 .

[28] Gizaw, F., Merera, O., Zeru, F., Bedada, H., Gebru, M.and Abdi, R.D. (2018): Sero-Prevalence and Socioeconomic Impacts of Peste Des Petits Ruminants in Small Ruminants of Selected Districts of Afar, Ethiopia. Journal of Veterinary Science and Technology,9(1): 2157-7579.

[29] Gizaw, F., Merera, O., Zeru, F., Bedada, H., Gebru, M.U. and Abdi, R.D. (2018): Journal of Veterinary Science \& Technology.

[30] Hailegebreal, G. (2018): Seroprevalence of Peste Des Petits Ruminants in Selected Districts of Siltie and Gurage Zones, South Region, Ethiopia. Journal of Veterinary Science and Technology, 9(2): 2157-7579.

[31] Hamdy, F.M., A.H. Dardiri, O. Nduaka, S.S. Breese and E.C. Ihemelandu, (2004): Etiology of the stomatitis pneumoenteritis complex in Nigerian dwarf goats. Can. J. Comp. Med., 40: 276-284.

[32] Jilo, K.(2016):Peste des petits ruminants (PPR): global and ethiopian aspects. A standard review. Global Veterinaria, 17: 142-153.

[33] Jones, B.A., Rich, K.M., Mariner, J.C., Anderson, J., Jeggo, M., Thevasagayam, S. and Roeder, P. (2016): The economic impact of eradicating peste des petits ruminants: a benefit-cost analysis. PloS one, 11(2): e0149982.

[34] Kahn, C. and Line, S. (2006): Editors, The Merck Veterinary Manual. White house Station, NJ: Merck and Co. Pulmonary Adenomatosis, pp.123-243.

[35] Kamissoko, B., Sidibé, C.A.K. Niang, M. Samake, K. Traoré, A. Diakité, A. and Libeau, G. (2013): Seroprevalence of peste des petits ruminants in sheep and goats in Mali. Revue D'élevageet De MédecineVétérinaire Des Pays Tropicaux, 66(1): 5-10.

[36] Kaukarbayevich, K.Z., 2009. Epizootological analysis of PPR spread on African continent and in Asian countries. African Journal of Agricultural Research, 4(9): 787-790.

[37] Kerdiles, Y.M., Cherif, B., Marie, J.C., Tremillon, N., Blanquier, B., Libeau, G., Diallo, A., Wild, T.F., Villiers, M.B. and Horvat, B.(2006):Immunomodulatory properties of morbillivirus nucleoproteins. Viral immunology, 19(2): 324-334.

[38] Khalafalla, A.I., Saeed, I.K., Ali, Y.H., Abdurrahman, M.B., Kwiatek, O., Libeau, G., Obeida, A.A. and Abbas, Z. (2010): An outbreak of peste des petits ruminants (PPR) in camels in the Sudan. Actatropica, 116(2): 161-165.

[39] Kwiatek, O., Ali, Y.H., Saeed, I.K., Khalafalla, A.I., Mohamed, O.I., Obeida, A.A., Abdelrahman, M.B., Osman, H.M., Taha, K.M., Abbas, Z. and El Harrak, M. (2011): Asian lineage of peste des petits ruminants virus, Africa. Emerging infectious diseases, 17(7): 1223.

[40] Leta, S. and Mesele, F. (2014): Spatial analysis of cattle and shoat population in Ethiopia: growth trend, distribution and market access. SpringerPlus, 3(1): 310.

[41] Libeau, G., Diallo, A. and Parida, S. (2014): Evolutionary genetics underlying the spread of peste des petitsruminants virus. Animal Frontiers, 4(1): 14-20.

[42] Madboli, A.A. and Ali, S.M. (2012): Histopathological and Immunohistochemical studies on the female genital system and some visceral organs in sheep and goat naturally infected by Peste des Petits Ruminants virus. Global Veterinaria, 9(6): 752-760.

[43] Mahapatra, M., Parida, S., Baron, M.D. and Barrett, T. (2006): Matrix protein and glycoproteins F and H of Peste-des-petits-ruminants virus function better as a homologous complex. Journal of General Virology, 87(7): 2021-2029.

[44] Mariner, J.C., Jones, B.A., Rich, K.M., Thevasagayam, S., Anderson, J., Jeggo, M., Cai, Y., Peters, A.R. and Roeder, P.L. (2016): The opportunity to eradicate peste des petits ruminants. The Journal of Immunology, 196(9): 3499-3506.

[45] Megersa, B., Biffa, D., Belina, T., Debela, E., Regassa, A., Abunna, F., Rufael, T., Stubsjøen, S.M. and Skjerve, E. (2011): Serological investigation of peste des petits ruminants (PPR) in small ruminants managed under pastoral and agro-pastoral systems in Ethiopia. Small Ruminant Research, 97(1-3): 134-138.

[46] Megersa, B., Biffa, D., Belina, T., Debela, E., Regassa, A., Abunna, F., Rufael, T., Stubsjoen, S.M. and Skjerve, E. (2011): Serological investigative of Peste des Petits ruminants (PPR) in small ruminants managed under pastoral and agro- pastoral systems in Ethiopia. Small Ruminant Research, 97(1): 134-138.

[47] Merkel, R.C. and Yami, A. (2008): Sheep and Goat Production Handbook for Ethiopia. 
[48] Munir, M., Zohari, S. and Berg, M. (2013): Immunology and immunopathogenesis of peste des petitsruminants virus. In Molecular Biology and Pathogenesis of Peste des Petits Ruminants Virus (pp. 4968).Springer, Berlin, Heidelberg.

[49] Nyamweya, M., Otunga, T., Regassa, G. and Maloo, S., 2009. Technical brief of peste des petitsruminants virus. ELMT Livestock Services Technical Working Group.

[50] OIE, (2008).International Office of Epizootics.Biological Standards Commission and International Office of Epizootics.International Committee, 2008. Manual of diagnostic tests and vaccines for terrestrial animals: mammals, birds and bees (Vol. 2). Office international des épizooties.

[51] OIE, (2012).Peste despetits ruminants. Manual of Diagnostic Tests and Vaccines or Terrestrial Animals 7 thedn. Paris;. http://bit.ly/32evA0X

[52] OIE, (2013).The OIE Terrestrial Manual, Chapter 2.7.11, Peste des petits ruminants.

[53] Osman, N.A., Ali, A.S. and Fadol, M.A. (2008): Rapid detection of Peste des Petits Ruminants (PPR) virus antigen in Sudan by agar gel precipitation (AGPT) and haemagglutination (HA) Tests. Tropical animal health and production, 40(5): 363-368.

[54] Radostits, O.M., Gay, C.C., Hinchcliff, K.W. and Constable, P.D. (2007): A textbook of the diseases of cattle, horses, sheep, pigs and goats. Veterinary medicine, 10, pp.2045-2050.

[55] Rahaman, A., Srinivasan, N., Shamala, N., Shaila, M.S. (2003): The fusion core complex of the Peste des petits ruminants virus is a six-helix bundle assembly. Biochemistry42: 922-931.

[56] Rima, B.K., Collin, A.M.J. and Earle, J.A.P. (2005): Completion of the sequence of a cetacean morbillivirus and comparative analysis of the complete genome sequences of four morbilliviruses. Virus Genes, 30(1): 113-119.

[57] Roeder, P.L., Abraham, G., Kenfe, G. and Barrett, T. (1994): Peste des petits ruminants in Ethiopian goats. Tropical animal health and production, 26(2): 69-73.

[58] Roger, F., GuebreYesus, M., Libeau, G., Diallo, A., Yigezu, L.M. and Yilma, T. (2001): Detection of antibodies of rinderpest and peste des petitsruminants viruses (Paramyxoviridae, Morbillivirus) during a new epizootic disease in Ethiopian camels (Camelusdromedarius).

[59] Saliki, J.T., House, J.A., Mebus, C.A. and Dubovi, E.J. (1994): Comparison of monoclonal antibody-based sandwich enzyme-linked immunosorbent assay and virus isolation for detection of peste des petitsruminants virus in goat tissues and secretions. Journal of clinical microbiology, 32(5): 1349-1353.

[60] Saravanan, P., Sen, A., Balamurugan, V., Rajak, K.K., Bhanuprakash, V., Palaniswami, K.S., Nachimuthu, K., Thangavelu, A., Dhinakarraj, G., Hegde, R. and Singh, R.K. (2010): Comparative efficacy of peste des petits ruminants (PPR) vaccines. Biologicals, 38(4): 479-485.

[61] Singh, R.P., Saravanan, P., Sreenivasa, B.P., Singh, R.K. and Bandyopadhyay, S.K. (2004): Prevalence and distribution of peste des petitsruminants virus infection in small ruminants in India. Rev Sci Tech, 23(3): 807-819.

[62] Sinnathamby, G., Renukaradhya, G.J., Rajasekhar, M., Nayak, R. and Shaila, M.S. (2001): Immune responses in goats to recombinant hemagglutinin-neuraminidase glycoprotein of Peste des petitsruminants virus: identification of a T cell determinant. Vaccine, 19(32): 4816-4823.

[63] Tibbo, M., Woldemeskel, M. and Gopilo, A. (2001): An outbreak of respiratory disease complex in sheep in central Ethiopia. Tropical Animal Health and Production, 33(5): 355-365.

[64] Woo, P.C., Lau, S.K., Wong, B.H., Fan, R.Y., Wong, A.Y., Zhang, A.J., Wu, Y., Choi, G.K., Li, K.S., Hui, J. and Wang, M. (2012): Feline morbillivirus, a previously undescribedparamyxovirus associated with tubulointerstitial nephritis in domestic cats. Proceedings of the National Academy of Sciences, 109(14): 5435-5440.

[65] Zakian, A., Nouri, M., Kahroba, H., Mohammadian, B. and Mokhber-Dezfouli, M.R. (2016): The first report of peste des petits ruminants (PPR) in camels (Camelusdromedarius) in Iran. Tropical animal health and production, 48(6): 1215-1219.

Citation: Seifudin Kassim Ahmed, "Review on Peste Des Petits Ruminants (Ppr) and its Economic Importance". International Journal of Research Studies in Biosciences. 2020; 8(8): 17-31. DOI: https://doi.org/10.20431/2349-0365.0808002.

Copyright: (C) 2020 Authors. This is an open-access article distributed under the terms of the Creative Commons Attribution License, which permits unrestricted use, distribution, and reproduction in any medium, provided the original author and source are credited. 